\title{
The Darkness Within ${ }^{1}$
}

\section{Ian Haig}

There is a substance that sits outside of the more familiar categories of bodily fluids and the emissions of pus, tears, vomit, semen, breast milk, urine, sweat and excrement; one that defies categorisations and reason. This unclassifiable substance coats the walls of your colon, your moist mucus membranes layered with a thick, slimy and terrible material which goes by the even stranger name of mucoid plaque. As an artist I am drawn to these 'off limits' regions of the body, my art practice premised on putting bodily reality back into the hygienic and sterile context of the gallery.

Mucoid plaque $^{2}$ is quite possibly the most disturbing of all body fluids, due largely to its unclassifiability. Unlike the secretions of tears, semen, urine, vomit and a host of other corporeal substances with a clearly understood bodily and biological purpose, the function of mucoid plaque is more mysterious and ambiguous. The alternative medicine fraternity claim that this disgusting material resides deep in our bowels, polluting our interiors with tentacles of pure abjection. It builds up as a lining along the colon walls of toxic material, harboring all manner of parasites, impacted fecal matter and colonic sludge. Mucoid plaque is post-shit - no mere excrement here - for mucoid plaque is shit transformed into an entirely new monster from the depths of your colon. The theory is mucoid plaque develops over a number of years as layers of mucus and food residue begins to coat the gastrointestinal tract. It is eliminated through colon cleansing, and a variety of herbal products targeted to cleanse the body of harmful plaques.

Nonetheless, it appears that mucoid plaque is generated by the body to protect itself from infection and is, after all, a sign of the body doing its job. It is indeed part of you: in fact, the disgust generated by such material is no doubt partly caused by the inability to contemplate and rationalise such material as being from within you, of being part of your body. Here the colon is not just the bodily portal between the exterior and interior, but also a kind of gateway to the excesses of the body: not only the

No. 9 / 2014 special issue: bodily fluids
This work is licensed under a Creative

Commons Attribution 3.0 License. 
evacuation tube of the unwanted, casting off what the body does not require as waste product, mucoid plaque manifests the misunderstood, the unknowable, the repressed and the unseen.

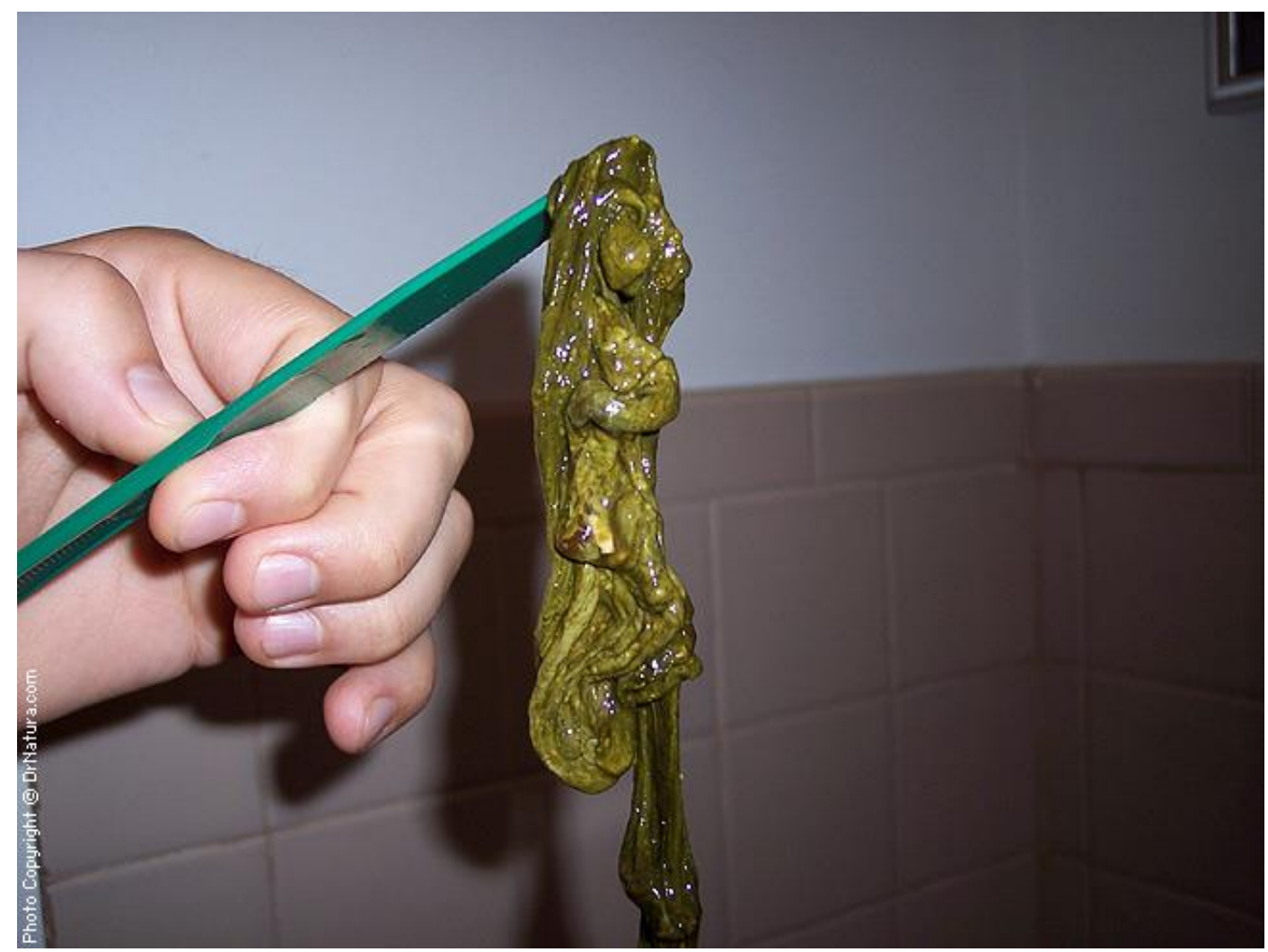

Mucoid plaque - Dr Natura

Mucoid plaque activates the physical sense of seeing, evoking a kind of intense staring born from disbelief for those who encounter it. We are unable to look away from such an abject substance, as we contemplate its incomprehensible existence within us. Film maker David Cronenberg has claimed that his earlier body horror films are concerned with "showing the un-showable and speaking the unspeakable" (1997, p. xvi). Mucoid plaque, like the realisation of Cronenberg's unshowability, represents the body turned inside out. We see something of the moist interior of ourselves that we are never meant to see, elements of the body that probably should remain in the dark.

The visual excess represented by mucoid plaque triggers a refusal of its very materiality - it appears to us more like a prosthetic special effect from a movie than a substance of the physical body. John Carpenter's The Thing (1982) comes to mind, a kind of other worldly goop that is not of the body but 
has instead invaded it: a horrible substance not of this world; an alien blob from another dimension; a whole new species of bodily material. And alongside spectacular disbelief, the ability to frame in language what it is we are seeing also flounders; no words are adequate to describe what has been made visible with the release of mucoid plaque from the body. Indeed, disgust and revulsion no longer seem either accurate or adequate adjectives to encompass the phenomenon.

Indeed, mucoid plaque is not actually believed by practitioners of allopathic medicine to exist; they claim it to be a fiction of our bodies created by the alternative health evangelists and their obsessions with bodily cleansing. This rejection is perhaps unsurprising: as Ralph Rugoff articulates (1995, p. 49), physicians often resort to using pictures as a teaching aid when words are inadequate to explain the unseen interior of the body and, as such, "medicine is as much about educating the eye". Both vision and language are put in crisis, the only recourse left to the medical community is wholesale denial.

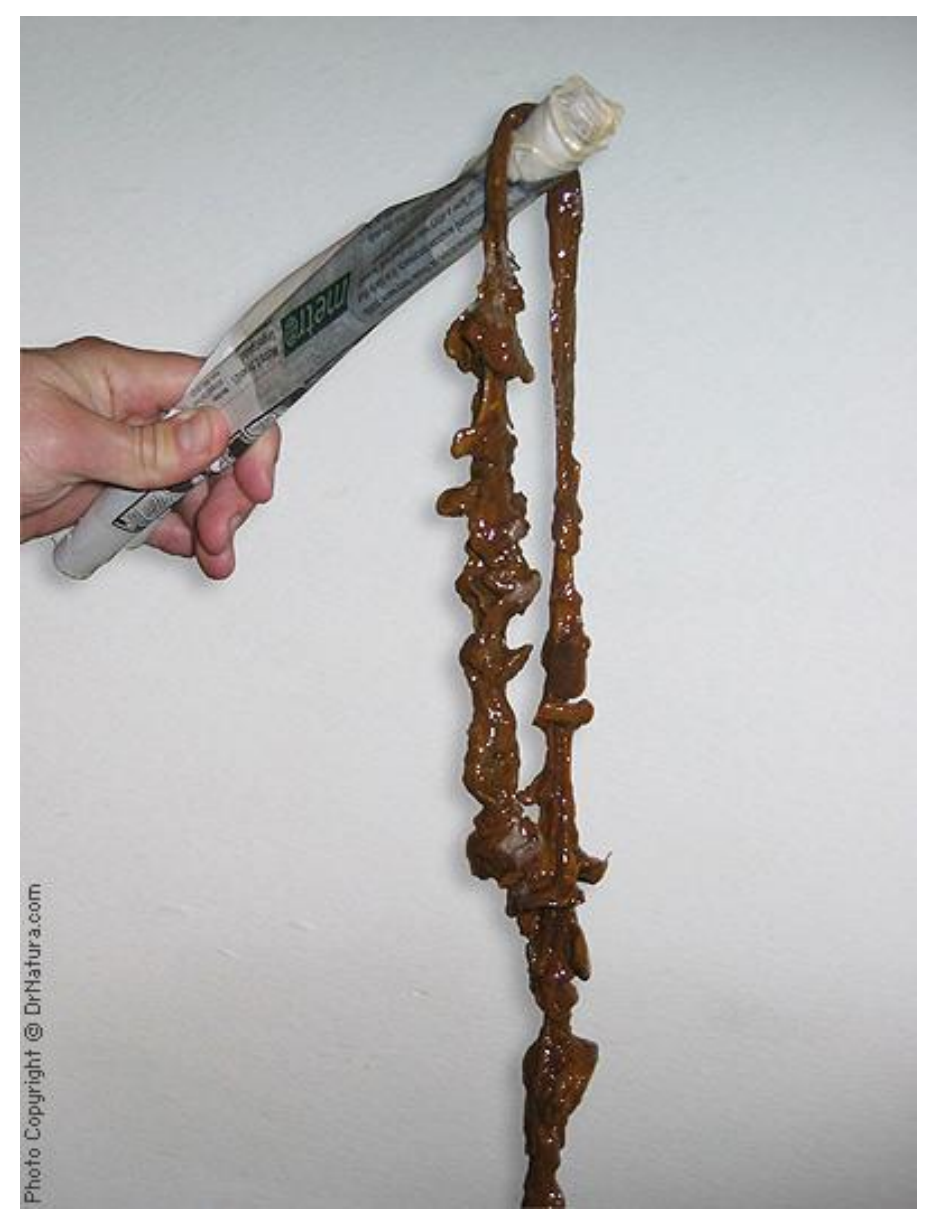

Mucoid plaque - Dr Natura 
Thus this thing, this putrid mass of weird bodily fluid, remains largely unknown and unacknowledged within conventional health circles. However, any casual Google image search reveals a plethora of disgusting examples of its existence. In the second decade of the twenty-first century, one would think we have finally gained an understanding of the body and its interior, that technology has provided us with every answer to the body's dark recesses, its organs entirely mapped out. However mucoid plaque confronts us and reminds us of the weird and putrid strangeness of our organic selves.

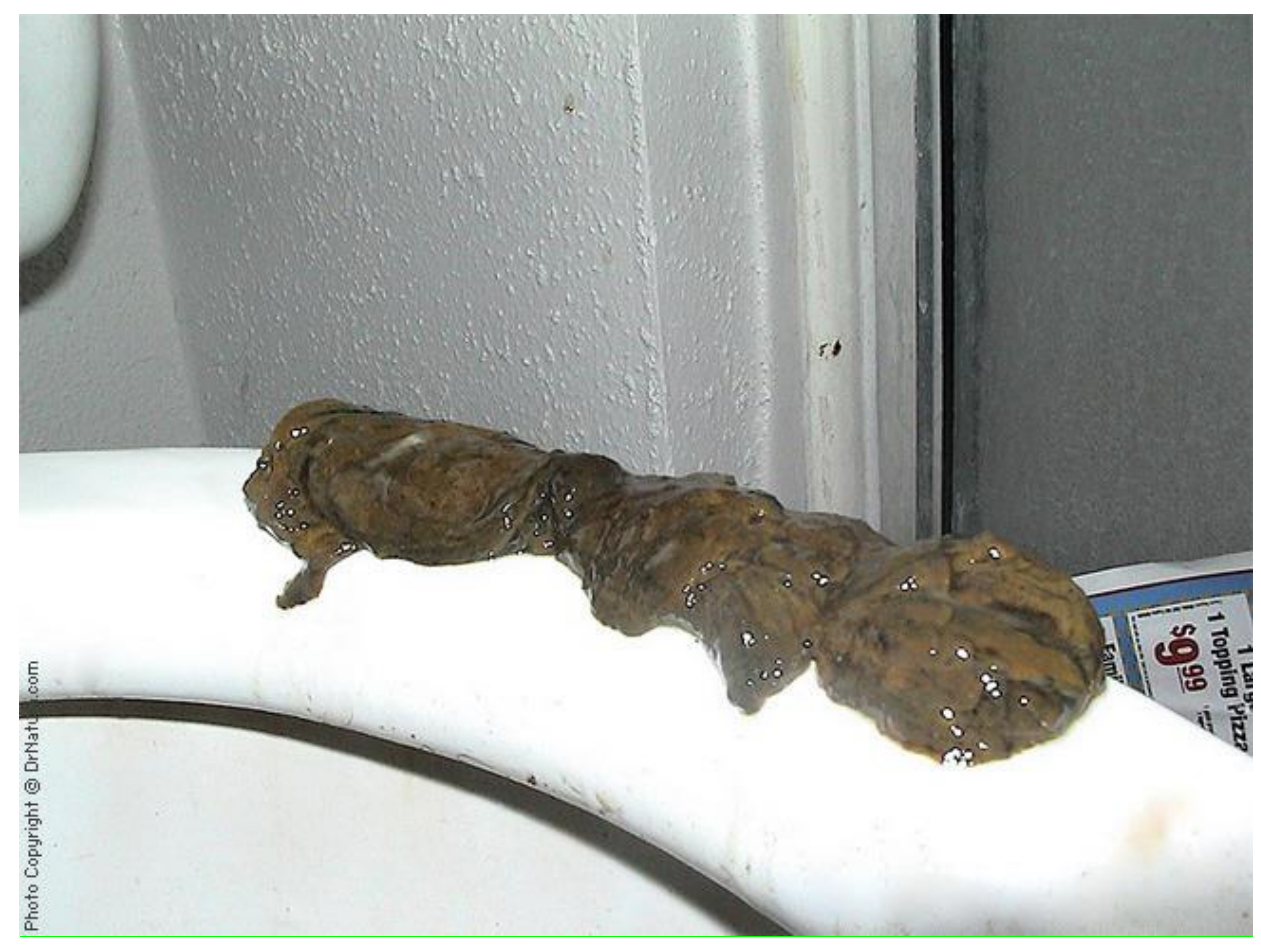

Mucoid Plaque - Dr. Natura

The ocular excess of mucoid plaque positions it as the car wreck of bodily fluids; like the morbid scene of an automobile accident, it is a material that is difficult to look at and difficult not to look at. Indeed, the substance makes its appearance regularly on various online alternative health forums such as Cure Zone and Google image searches. While it may be argued that we are losing sight of the materiality of the body in the digital age, conversely the body is entirely over-visible within certain online communities. The body on forums like Cure Zone is a body in a state of crisis, indeed in browsing the site one gets the feeling that the natural state of the body is that of disease, illness and not the body of health and well-being. 
Cure Zone, for instance, features many forums devoted to the internal body and its associated pathologies, from gall stones, parasites and worms to other unrecognisable bodily secretions and fluids such as mucoid plaque. Images of inexplicable excreted fecal matter and all manner of other bodily material passed by one's bowel movement regularly makes an appearance in Cure Zone user postings. Cure Zone is ultimately a site devoted to assisting its user network to find alternative treatments to difficult medical conditions. However one can't help thinking that there is also a degree of voyeurism at play here, which revels in the freak show of the interior body on display, and in things revealed about our bodies that one would prefer not to know. The internal body here is rendered entirely visible and exposed, taking Facebook's notion of the visible self - where every personal detail is revealed online - to strange and perverse new bodily heights.

Indeed my own discovery of the mysterious mucoid plaque was via the web, through a listing for an alternative health product. The body in crisis it would seem are well and truly alive online, if not the body we are familiar with.

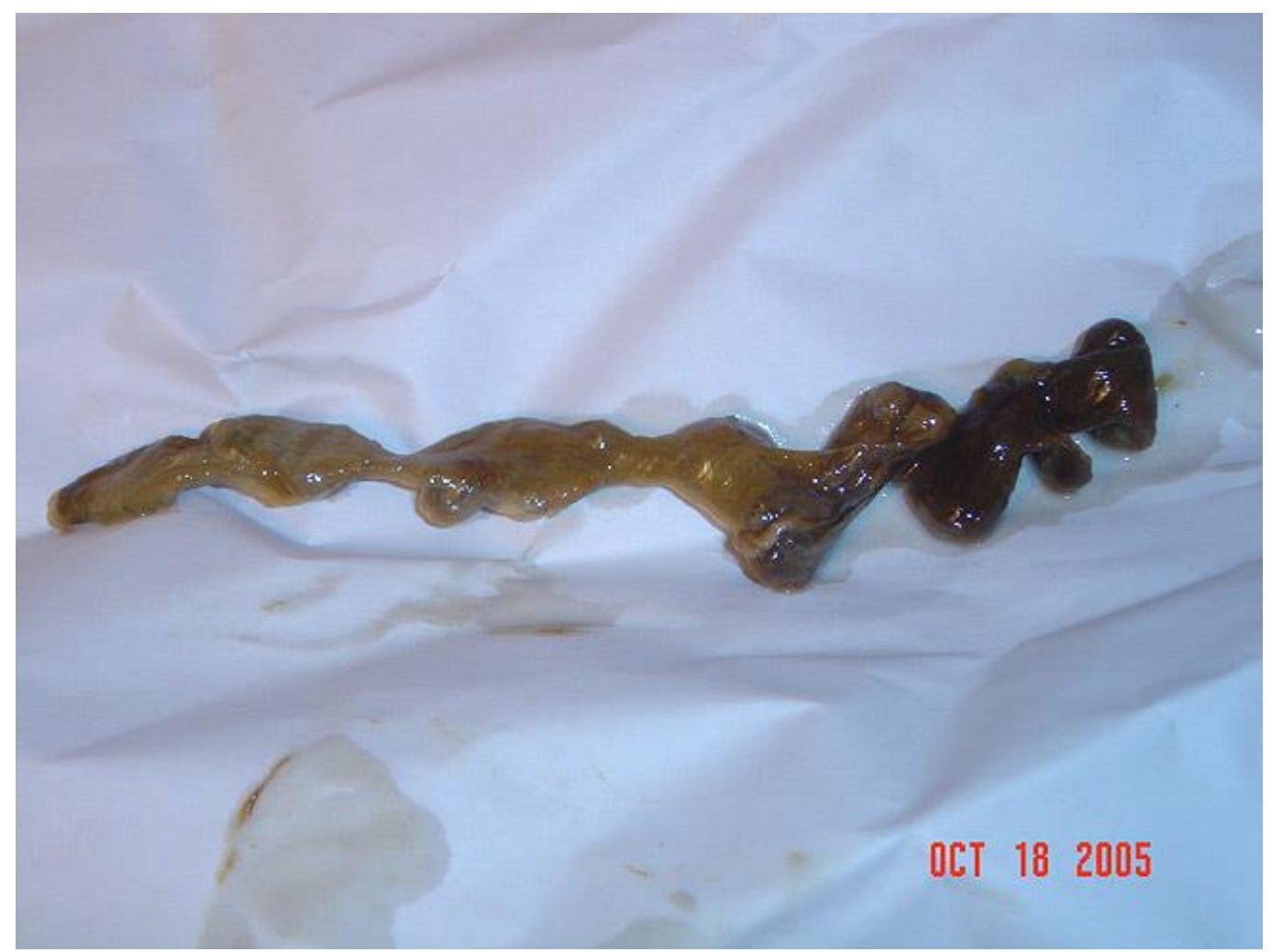


The entire detox movement, involving purging cures and cleansing regimes, is aimed at targeting the unseen, interior body, as the well of disease and corruption of bad bacteria and toxic overloads. Bizarrely, the rise in alternative therapies like detoxing and colonic irrigation, with their intense focus on the interior body, is occurring in an age of extreme exteriors of the body: the popularity of these purification methods are now almost directly proportionate to the popularity of beautifying plastic surgery procedures, liposuction, botox injections and other external body makeovers. The contemporary body exists in an amplified state of hyper-extended interior/exterior.

Yet the goop of mucoid plaque introduces a problematic in-between state into this internal-external binary; it suggests a transition of one body mass melting into another. As William lan Miller (1998, p. 106) points out, materials that are slimy, gooey and squishy are disgusting to us because they represent things in a state of flux. Like life, "there is no fixed point. All is flux and in flux" (Miller, 1998, p. 106), a series of loose and slippery recurrences, for nothing stands still or is static.

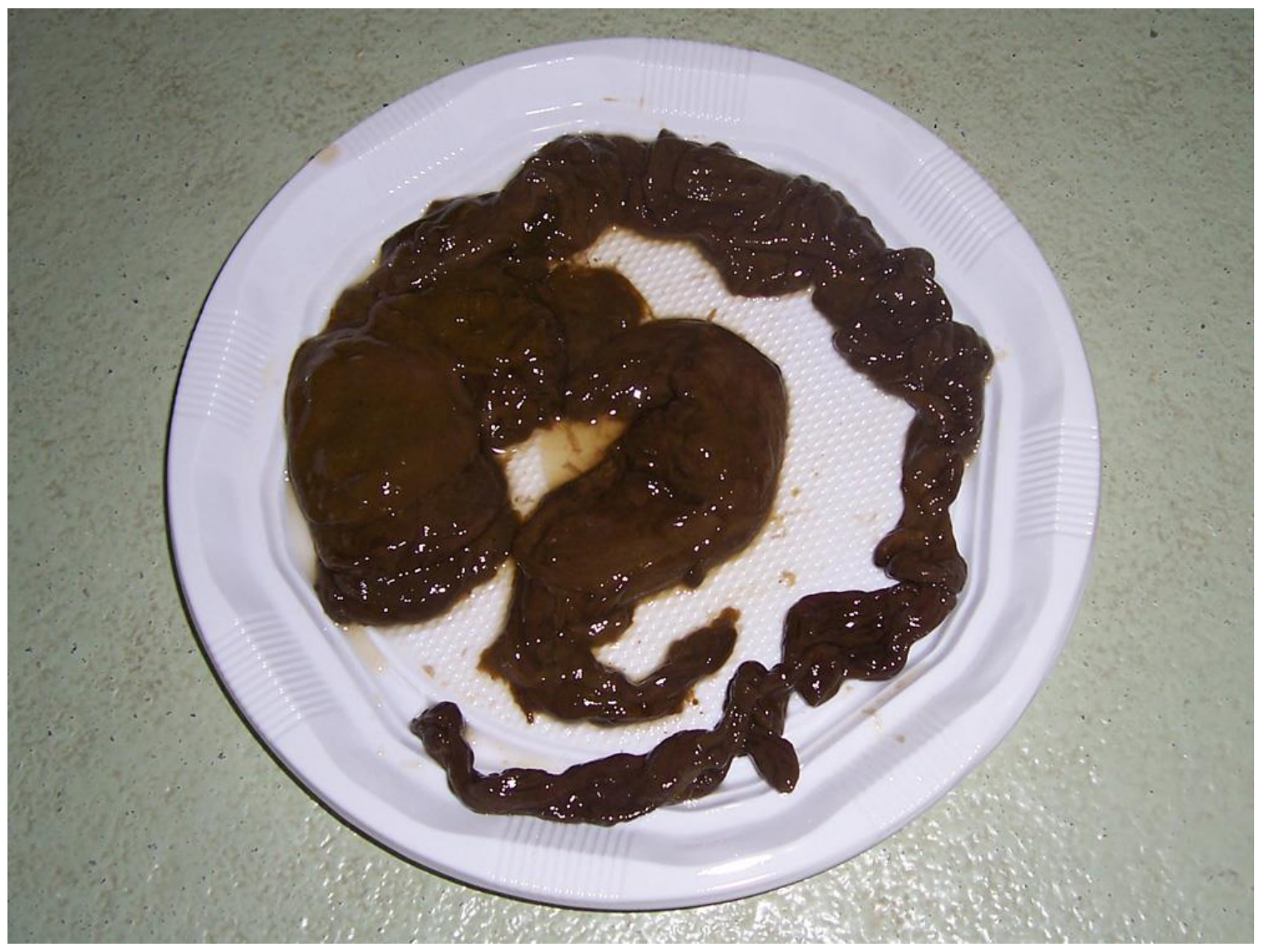


One of the more disturbing aspects of mucoid plaque, then, is that it appears to be part of us, unlike other bodily fluids which almost operate on an ontological level of being separate. A discharge, an evacuation of the bowels, or fluid ejaculate - bodily fluids are largely on their way out of the body. Mucoid plaque, however, remains buried, in some cases for years hidden and deathly quiet inside one's bowels. It is entirely unseen; its release is often met with the idea that one has actually removed part of their own colon, as mucoid plaque, having spent many years inside the warm, wet and dark corners of your body, retains the shape of the colon once it exits. It is the body inverted, as the exterior and interior body collapse into one another.

Finally, mucoid plaque challenges the very concept of disease itself. While the perception exists that diseases like cancers and tumors are somehow separate from the body while inherently being part of it, mucoid plaque is implicitly bodily material that has suddenly made itself visible. Unlike other diseases, mucoid plaque does not attack the body like some perceived external force, but rather forms a weird and disturbing symbiotic relationship to the body. It is the incarnation and manifestation of bodily disease itself. Indeed, Kellogg Cornflakes founder and alternative health evangelist John Harvey Kellogg declared as much when he claimed death begins in the colon when discussing his theory of autointoxication and the body being polluted by its own toxic overload. (2000, p. 183)

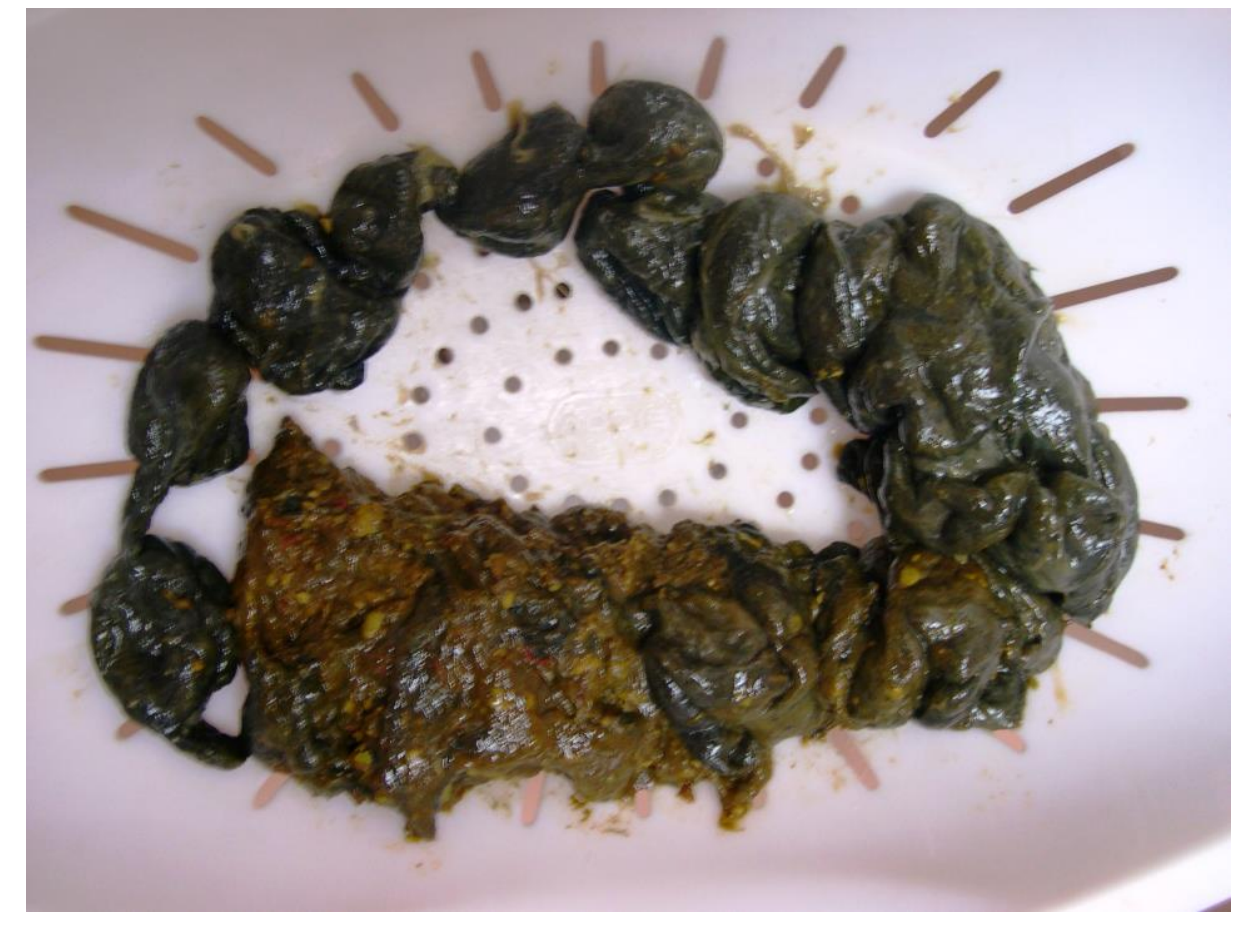


Physicians in seventeenth-century London were compelled to dissect the body in order to understand it in an integrated manner as a series of interconnected and related organs - of the blood pumping through the heart, the bile secreted from the gallbladder Before an understanding of cell biology, evolutionary theory and the development of sophisticated microscopes, a search for the interior body was no doubt connected to the larger quest for a search for the human soul.

In such a context, mucoid plaque takes on an entirely abject meaning: deep within the body, this foul and corrupt bodily material is more like the bodily abyss of hell than the ethereal house of the soul. Mucoid plaque would appear as anti-life and anti-human matter; it is death itself inside the warm cavity of our body and a reminder that our very bodies carry the seeds of our own destruction deep within.

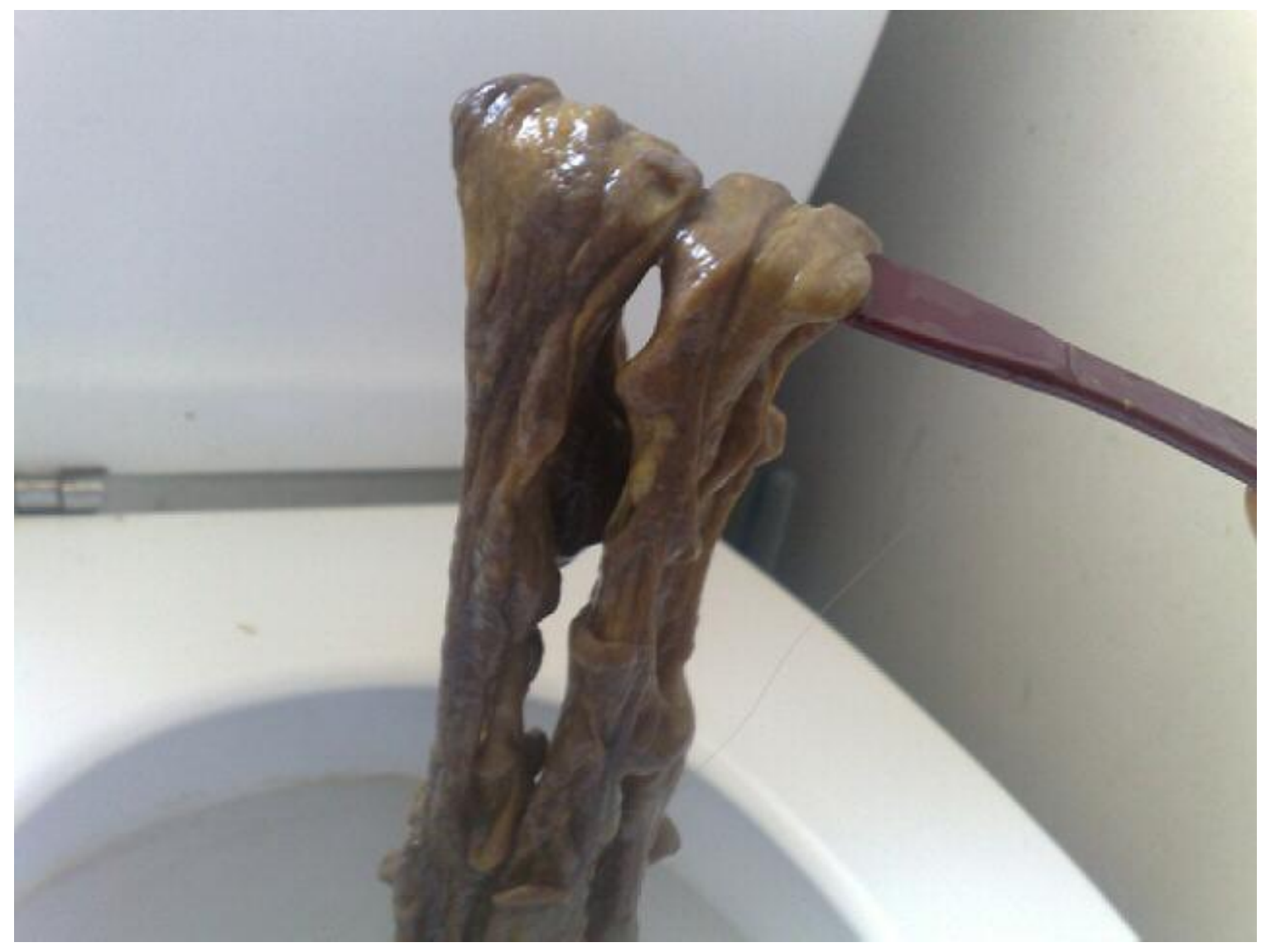


Georges Bataille too comments on feces and its relationship to death: "The horror we feel at the thought of a corpse is akin to the feeling we have at human excreta" (1986, p. 57, my emphasis). As Bataille articulates there is an implicit relationship to death and shit. In the end, mucoid plaque is possibly death incarnate, a death that we carry around with us every day in the form of a bodily fluid that we are only just beginning to see, let alone understand.

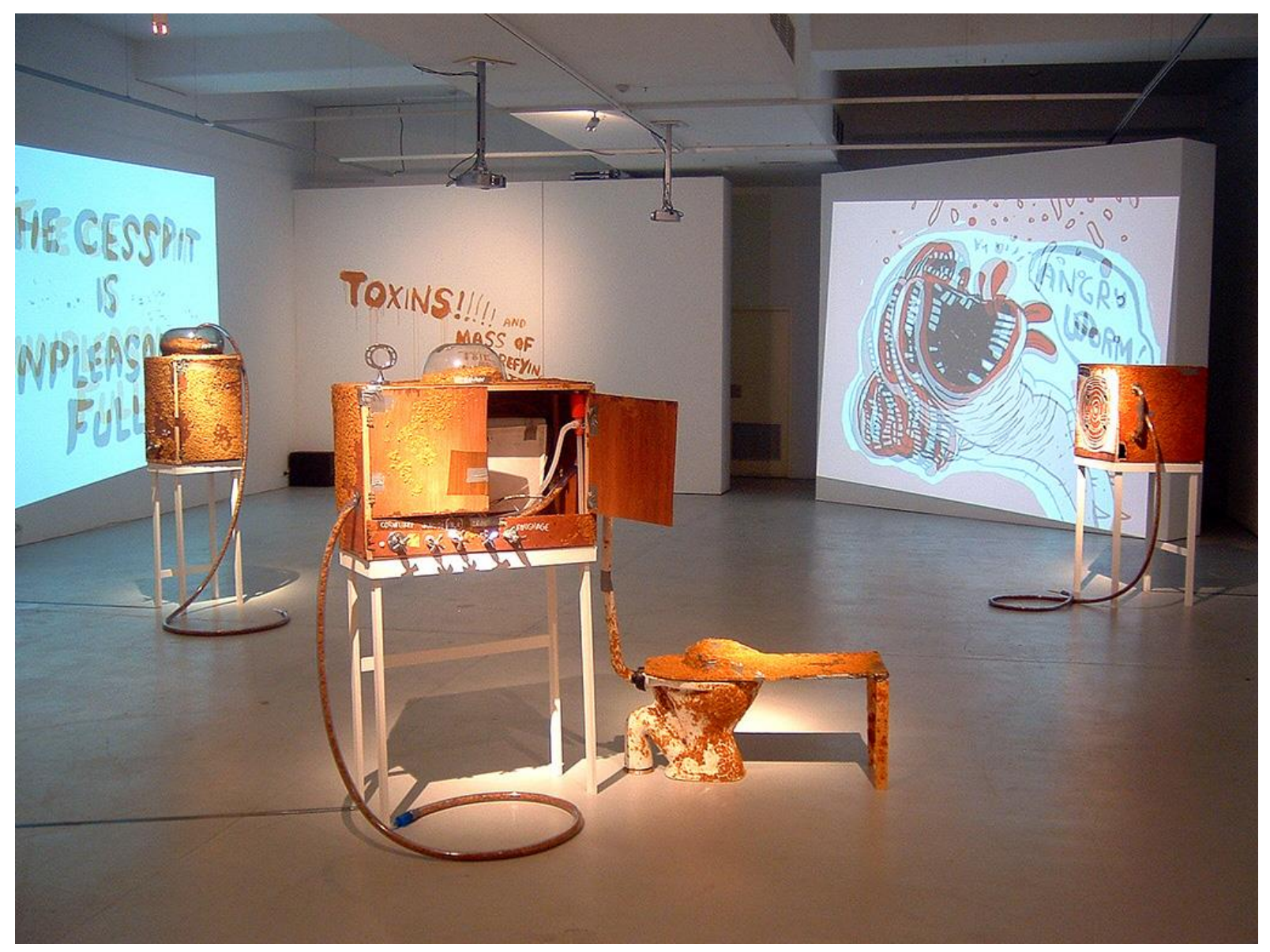



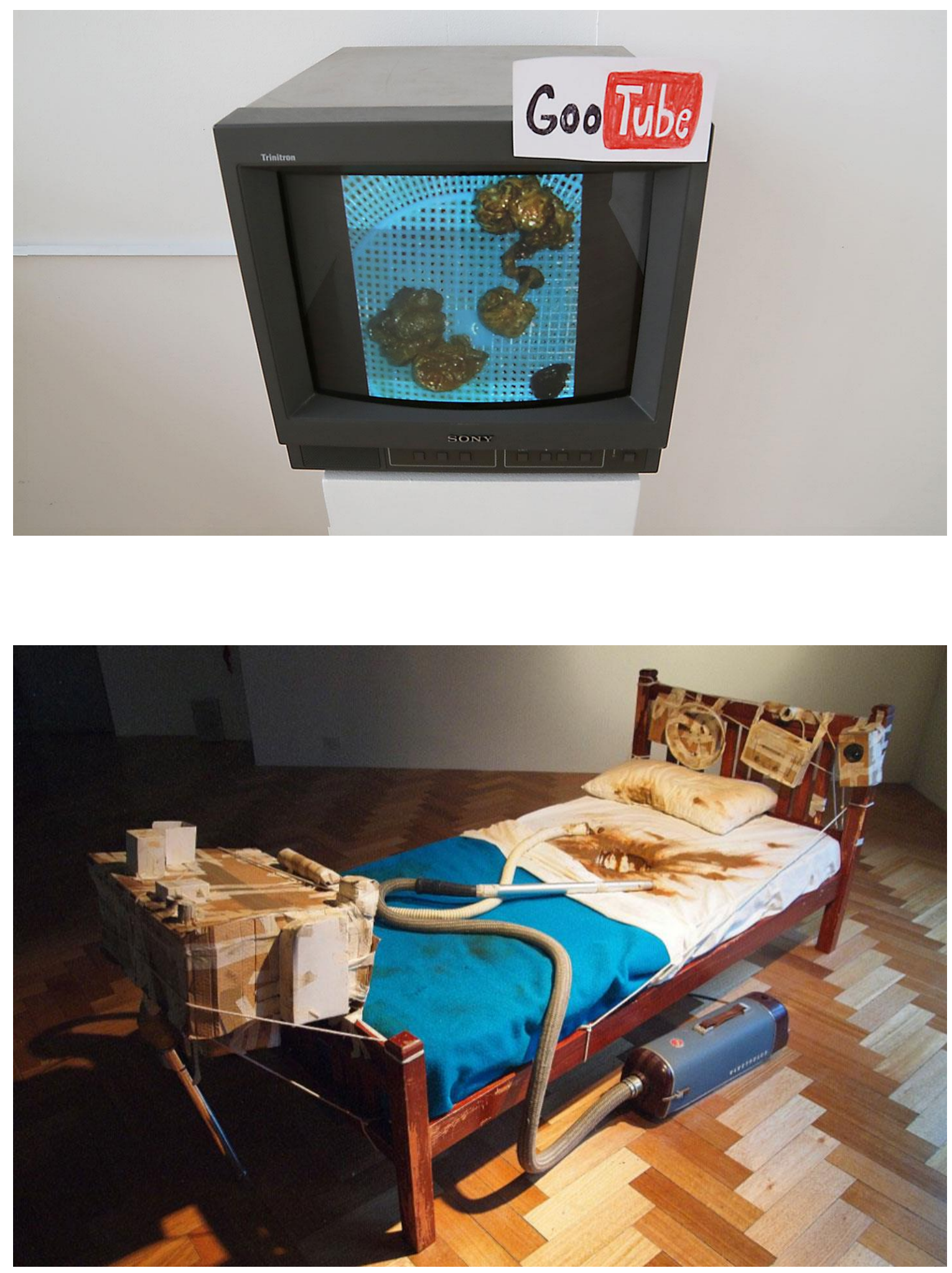

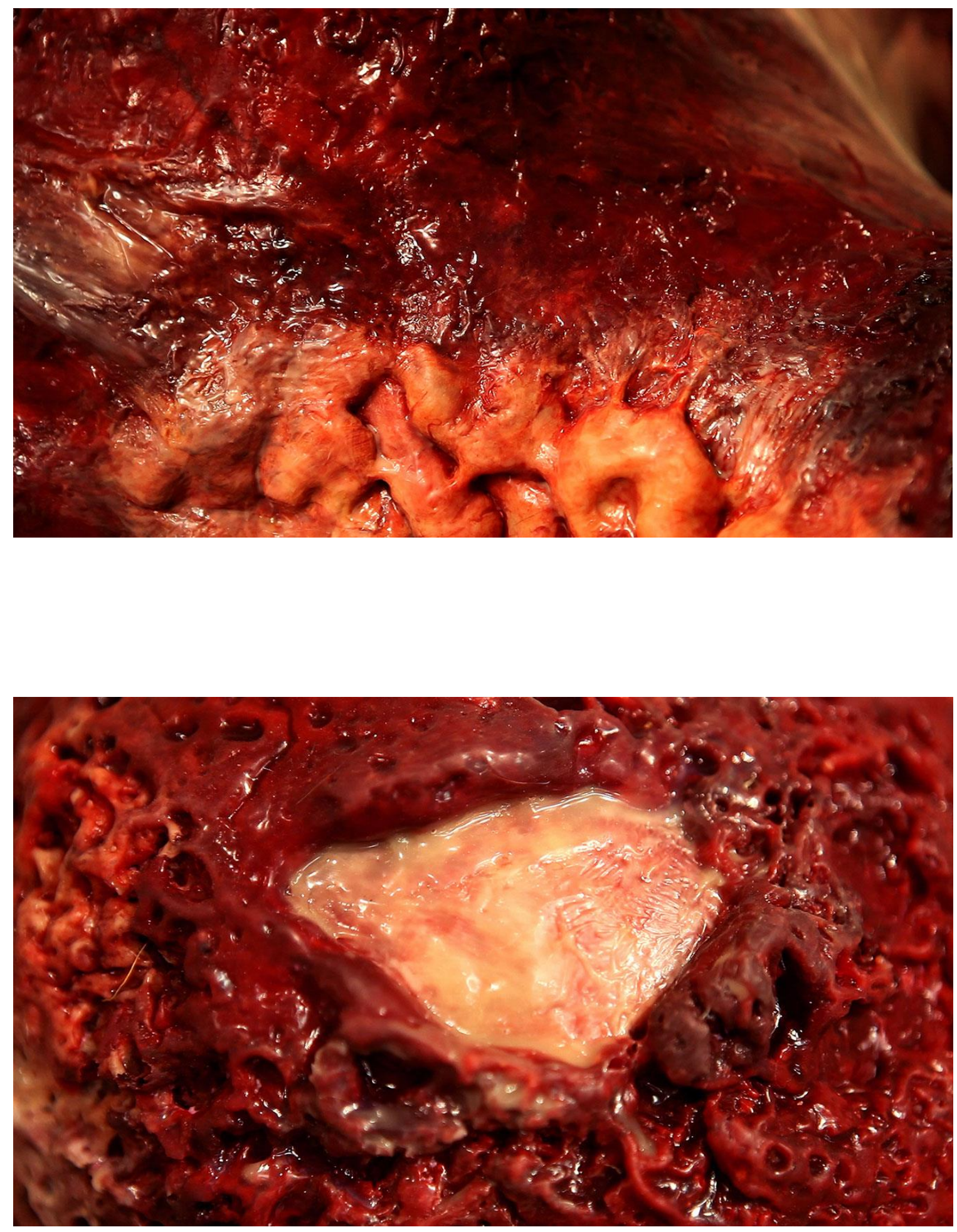

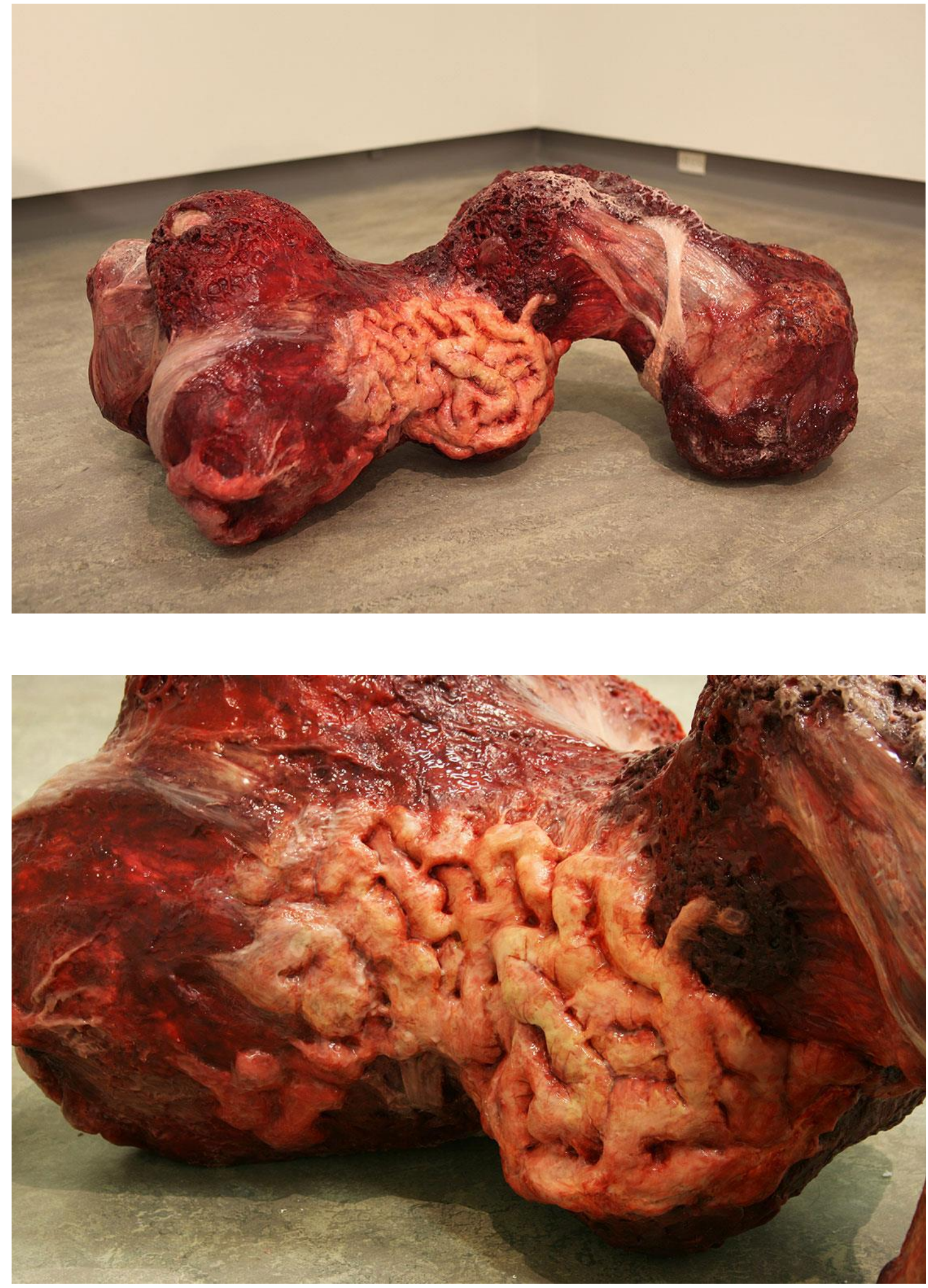


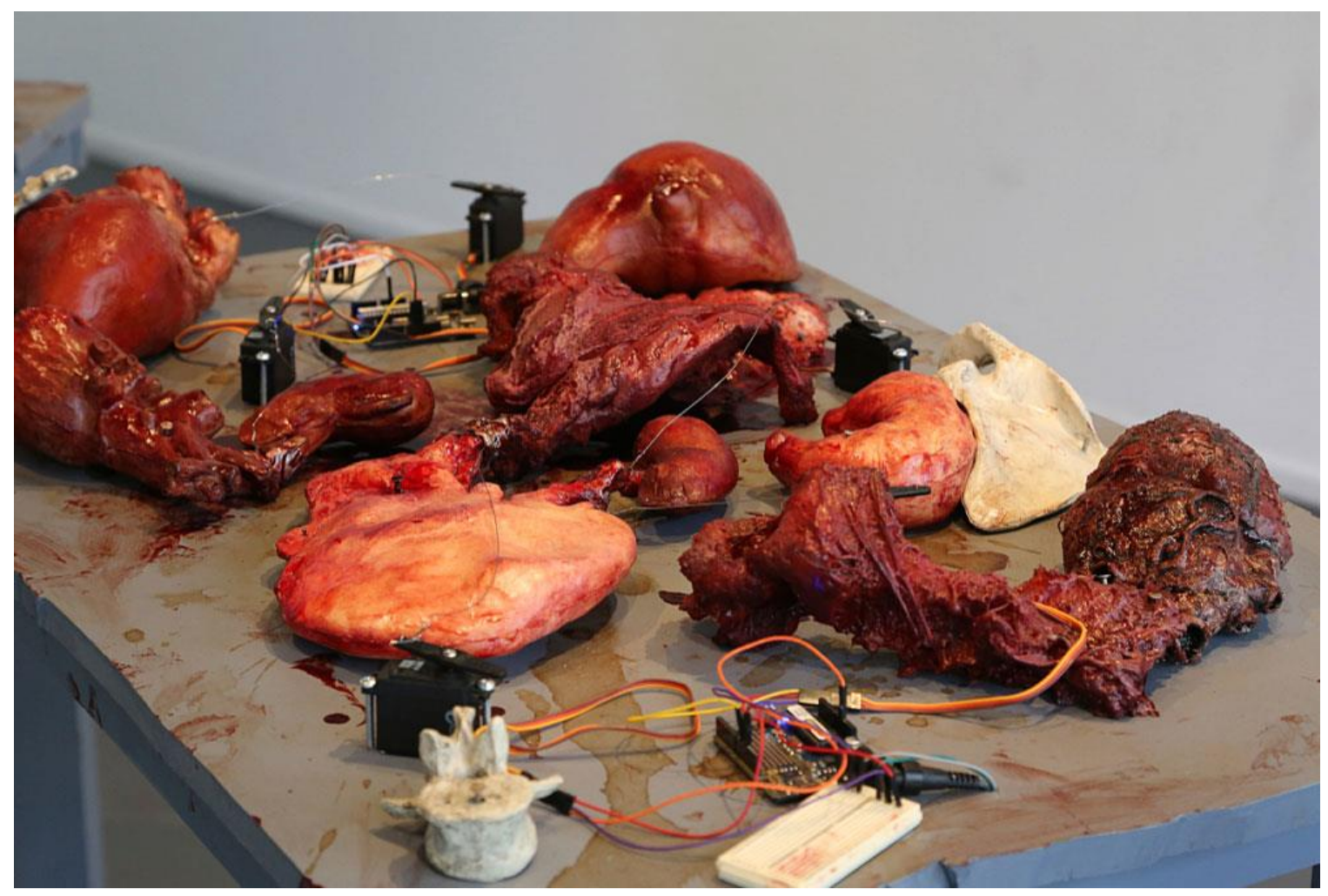

\section{Notes}

${ }^{1}$ Note: all images have been reproduced from Google.

${ }^{2}$ For a detailed explanation of mucoid plaque see http://detox.net.au/mucoid-plaque-and-mucus/ (viewed 23 ${ }^{\text {rd }}$ Feb, 2014).

\section{Bibliography}

Bataille, G., 1986. Erotism: Death and Sensuality. San Francisco: City Lights Books.

Dr Natura (company which sells colon cleansing products including Colonix, for the removal of mucoid plaque)

Miller, W., 1998. The Anatomy of Disgust. Cambridge, MA: Harvard University Press.

Rodley, C., 1997. Cronenberg on Cronenberg. London: Faber \& Faber.

Rugoff, R., 1995. Circus Americanus. London: Verso. 
The Thing. 1982. [Film] Directed by John Carpenter. USA: Universal Pictures and Turman-Foster Company.

Whorton, J., 2000. Inner Hygiene - Constipation \& the pursuit of Health in Modern Society. New York: Oxford University Press. 